\title{
Cuidado!!!: \\ Malos educadores afectan la sociedad
}

Aldo Yametti Vargas.

Estudiante Trabajo Social Universidad Alberto Hurtado

El artículo aborda la compleja relación del impacto de los mass-media en la población. Cómo a partir de mensajes mediáticos se crea una realidad que es introyectada por la población y actúa en consecuencia. Internet, Televisión, Radio y prensa escrita van colocando los temas de conversión cotidiana de la gente común e influyendo en sus comportamientos cotidianos.

Palabras clave

Manipulación / televisión / Internet / radio / prensa / realidad 


\section{Abstract:}

The article approaches the complex relationship of the impact of mass-media in the population. How, from media-generated messages, a reality is created that is digested by the people who act consequently. Internet, Television, Radio and the written press introduce the daily topics of change for common people and influence in their daily behaviors.

\section{Key words}

Manipulation / television / Internet / radio / press / reality 
$\mathrm{E}$ s indudable que el mundo ha cambiado, la realidad de las sociedades medievales es diametralmente distinta a la de los países modernos. Hoy estamos frente a un escenario marcado por la globalización, por cambios gradualmente más vertiginosos. Los medios de comunicación masivos, las vivencias diarias y las anécdotas que día a día sabemos a través de nuestras conversaciones, nos relatan entre líneas la sensación de que en la sociedad actual existe una crisis valórica, un individualismo, una impresión de pérdida de interés por lograr metas comunes y de creer en aquellos grandes proyectos de sociedad que esperábamos alcanzar mediante la causa común y la asociación entre personas.

La humanidad actualmente está contagiada de un desinterés, sumergida en una actitud de confinar a segundo plano un tema de suma importancia como es el de llevar a cabo un proyecto llamado sociedad, una indolencia frente a asuntos de importancia para nuestra constitución como sujetos y como ciudadanos, de temas de relevancia nacional e internacional como, por ejemplo, la implicancia que puede tener hoy que aumente el precio del petróleo.

Hoy, las portadas de los diarios no destacan las realidades que sí importan conocer en el país, los temas que realmente aporten para nuestro desarrollo dentro de una sociedad, sino que son un millón de veces más importantes los entretelones de las peleas entre dos figuras conocidas 
dentro del escenario farandulero o las razones de por qué no se casó el futbolista con la modelo. Además, con la gran innovación que nos trae Internet, hay una posibilidad de ver más allá de nuestras fronteras, abrir aun más nuestra visión de mundo, lo que también implica arriesgarnos a diversas influencias externas que, pese a causar sensación en los países, puede causar mal influjo y, de paso, trae un quiebre en la identidad nacional y, por lo tanto, no existe un reconocimiento a lo nuestro, a nuestros orígenes.

Lo más lamentable de todo es que nuestros niños están siendo los receptores de toda esta basura que nos presenta la sociedad y, al caracterizarse éstos por su pasividad en la recepción de las pautas de comportamiento, estamos paulatinamente alejándonos como sociedad de la labor tan noble que tiene la educación desde siempre: "el niño, al entrar en la vida, no aporta más que su naturaleza de individuo. Por tanto, la sociedad se encuentra, por así decirlo, a cada nueva generación, en presencia de una tabla rasa sobre la que se ve obligado a edificar partiendo de cero. Es preciso que, por las vías mas rápidas, al ser egoísta y asocial que acaba de nacer, superponga otro capaz de llevar una vida social y moral. En pocas palabras, ésta es la misión de la educación y pueden ustedes percatarse de toda su grandeza. ${ }^{1}$

Dentro de esta labor educativa, son los maestros y la familia los principales agentes responsables de entregarles todos aquellos valores, todo lo esencial para desenvolverse dentro del entorno con el cual interactúa. Pero, existen otros personajes que son responsables de las desgracias que la sociedad actual protagoniza y que tienen una influencia cada vez más notoria en la vida de los seres humanos; son "los malos educadores" dentro de la sociedad, personas que han hecho estragos tanto en la vida colectiva como en la más privada, las más particular.

1 DURKHEIM, Emile. La educación moral, Madrid, Editorial Trotta, 2002, Pág. 36. 
Éstos se anidan principalmente en los medios masivos de comunicación: en diarios, revistas, televisión, Internet, incluso en la radio, y una innumerable cantidad de otros que no viene al caso nombrarlos. Todos tenemos la "conciencia" de que los medios, en la actualidad, están cumpliendo un papel dentro de la sociedad: entregar "sana" entretención e informar. Pero ahora, la sociedad está exigiendo un mayor desafío a los medios: EDUCAR.

A lo largo de este artículo, no podemos perder de vista la importancia que tienen los mass-media como nuevo medio de referencia del mundo exterior y como factor cada vez más determinante: primero la televisión , por el hecho de mostrar unas de las primeras imágenes que al niño llama la atención; posteriormente, los diarios y las revistas, cuando tiene la habilidad de la lectura, hasta llegar, cada vez más prematuramente, al manejo de Internet donde no hay mayor protección al menor frente a las imágenes que pueden presentar algunas páginas) A través de ellos, el niño recién comienza a conocer el mundo, la realidad. A esto se suma la enseñanza de los padres y el sistema educativo que dentro de su proceso de socialización ha proporcionado desde siempre.

Si nos detenemos un momento y tomamos el sentido de lo que nos dice Durkheim respecto a la educación, que tiene como una de sus funciones el formar y adaptar al niño a pautas morales de conducta de la sociedad ${ }^{2}$, la gran interrogante que debemos responder nosotros como sociedad debe ser la siguiente: ¿Cómo la educación puede cumplir su función frente a un escenario tan adverso en el ámbito valórico, donde los niños están recibiendo cada vez mayor influencia, acceso y baja calidad de los medios de comunicación? ¿Qué pasará en las próximas generaciones con nuestros niños? ¿Qué recibirán posteriormente?

2 DURKHEIM, Emile. Educación y Sociología, $2^{\circ}$ ed., México, Editorial Colofón, 1989, Pág. 30. 
Nuestro recorrido pretenderá tratar de responder a estas interrogantes desde la postura de la Sociología de la Educación que el sociólogo francés Emile Durkheim nos presenta en sus textos Educación y Sociología y La Educación moral. El camino pasará por muchas estaciones donde se reflexionará y criticará a los medios de comunicación por la falta de compromiso, de interés y la evasión que han presentado frente a algo de vital importancia y que nos hace "grandes" personas como es la educación. Pero, también visitaremos dentro de esta ruta tan pedregosa paisajes donde veremos iniciativas que han pretendido aminorar las graves secuelas que puede traer esta dupla "mala educación - medios de comunicación" que, junta, pueda ser dinamita.

Un buen punto de partida consiste en saber la definición de educación y de los medios de comunicación social desde diversos puntos de vista. Durkheim dice que la educación en la sociedad es: "la acción ejercida por las generaciones adultas sobre las que todavía no están maduras para la vida social. Tiene por objeto suscitar y desarrollar en el niño cierto número de estados físicos, intelectuales y morales que exigen de él la sociedad política en su conjunto y el medio especial, al que está particularmente destinado ${ }^{\prime 3}$.

El Presidente de la República, Don Ricardo Lagos Escobar, se refiere a la educación como: "la base para humanizar la vida de las personas, para una efectiva igualdad de oportunidades, para superar la pobreza y para integrarnos competitivamente a un mundo que hace un uso cada vez más intensivo del conocimiento y de las tecnologías" ${ }^{4}$.

En cambio, el Departamento de Investigación de la Universidad de Playa Ancha, por medio de uno de sus estudios dice que los medios masivos de comunicación en su relación con la educación se: "han transformado

3 Ibíd., Pág. 70.

4 Revista de Pedagogía, SANTIAGO, N413, Nov / Dic 1999, Pág. 14. 
en una agencia de transmisión cultural. Particularmente se destaca el papel que, al respecto juega en la sociedad contemporánea la televisión, medio que se ha convertido en un medio socializador fundamental, entre muchas otras razones, porque ningún otro consume más tiempo a los niños y niñas que éste" ${ }^{\prime \prime}$.

Detrás de esta frase, existe un diagnóstico sumamente duro, pero real. Existe, está rodeando en nuestra sociedad como un fantasma; el niño no está prefiriendo un buen libro, una buena obra de teatro, una conversación enriquecedora con su familia, con su entorno, se ha ido por el camino más fácil, el sentarse frente a una caja chica y esperar ver imágenes sin tener la capacidad de ver nada productivo, esperando nada.

Rubí Carreño, junto a otros autores, definen a los medios de comunicación social como: "Aquellas formas institucionalizadas o instrumentos técnicos - artísticos que sirven para producir y transmitir mensajes dirigidos a una gran cantidad de público, por grandes extensiones de espacio y tiempo" ${ }^{\prime \prime}$. Además, enfatizan que "La necesidad de informarse es uno de los principales derechos de los seres humanos y, también, uno de los grandes pilares de una convivencia democrática. A través del acceso a la información, las personas pueden construir una visión más pluralista del acontecer, pues tienen la posibilidad de conocer las distintas miradas sobre un mismo hecho. En este sentido, los medios de comunicación social desempeñan un rol muy importante, pues deben contribuir a una entrada equiparada de las diversas corrientes de opinión existentes".

Es preciso, ahora, hacer un análisis de la situación y la posición que cada medio de comunicación masivo tiene en este momento dentro de la sociedad, para luego ver qué

5 Depto de Investigación, Universidad de Playa Ancha, Estudiantes, Profesores y Madres: Convergencias y Divergencias en su Evaluación, Valparaíso, 1998, pág. 1.

6 CARREÑO, R; PAEZ,G. Lengua Castellana y Comunicación, Ed. Mare Nostrum, Santiago de Chile, 2001, pág 56. 
relación tiene y qué puede hacer la educación frente a este escenario que presentaremos a continuación:

\section{1) Televisión:}

La televisión es un vehículo comunicacional de primer orden en donde el niño recibe las primeras representaciones del mundo. En esta etapa, él es todo recepción y conserva todo lo que recibe en esta fase formativa. Pero, la sociedad no ha aprovechado este medio: sólo entrega entretención de dudosa calidad, no considerando el aprendizaje para su desarrollo intelectual.

La televisión, hoy en día, tiene un poder de convocatoria de grandes magnitudes, tiene un poder de hipnosis y de convencimiento tal en el niño que es capaz de recibir cualquier cosa de ella, sin siquiera dudar de la veracidad de lo que está frente a sus ojos. Lamentablemente, este ser de corta edad se convierte en una computadora, recibe información y la interioriza sin filtrar.

Esto es comparable con la educación que, a principios deL siglo, e incluso en la actualidad, nos presenta Durkheim en Sociología y Educación donde el niño tiene un rol pasivo en el proceso educativo, ya que la voluntad del niño se caracteriza por ser muy básica a su corta edad. Frente a esta ventaja que presenta el educador como una persona con mayor superioridad en edad en saberes, en conocimientos, en experiencias, será fácil ejercer su poder sobre el educando. Lo mismo sucede con los medios de comunicación. En una situación de "inocencia" que vive el niño en sus primeros años de vida y le llama todo la atención, es sumamente susceptible a captar y a repetir lo que la televisión a través de sus imágenes reproduce de la sociedad. En ambos casos, es muy accesible al contagio del ejemplo, muy propenso a la imitación.

La televisión chilena, hoy en día, no está facilitando ni ayudando a una de las tantas labores de los buenos educa- 
dores y de la educación: a saber. Una forma de comprobar lo antes expresado es presentar gente común y corriente en un foro de un diario capitalino, los cuales son sometidos a la siguiente interrogante: ¿Qué le parece la calidad de la programación actual? Detrás de las siguientes respuestas, se pueden ver realidades que impiden que está situación mejore, avance poco. Los comentarios hablan por sí solos:

$\rightarrow \quad$ Opinión $\mathbf{N}^{\mathbf{0}} \mathbf{1}$ : "Todos han dicho ya que la programación de la televisión abierta en Chile es mala, mediocre, aburrida, etc. Pero, lo que es funesto es que en nuestra sociedad la televisión ha pasado a ser un agente educador (aunque los ejecutivos digan que la televisión está para entretener e informar), pues muchos niños y adolescentes buscan sus modelos de actitudes en los personajes de la pantalla chica. Innegablemente, eso es responsabilidad de los padres. Pero, los medios de comunicación también tienen una gran responsabilidad con esos televidentes, tienen gran influencia sobre esos niños y jóvenes...jMEDIOS: NO NIEGUEN SU ROL EDUCADOR Y ASÚMAN$L O !^{\prime \prime}$

$\rightarrow \quad$ Opinión $\mathbf{N}^{\mathbf{2}} \mathbf{2}$ : "De qué sirve dar una opinión objetiva y realista sobre el actual estado de la televisión chilena, si, aunque se indiquen las debilidades y fortalezas de un determinado programa, éste se va a realizar de la manera que genere mayor audiencia, lo que se traduce en un espacio más atractivo para los auspiciadores, no importando al nivel que se tenga que llevar la televisión para lograr dicho fin, aunque esto vaya en perjuicio de un crecimiento sano y con valores para los adultos y pequeños". ${ }^{8}$

7 LA SEGUNDA, Foro ¿Qué le parece la calidad de la programación actual?. Gabriela Alejandra Horta Pizarro, 11:06am, 20-03-2003, Chile en http://www.lasegunda. $\mathrm{com} /$ edicionOnLine/Interaccion/Foros/foroactual.asp?pagina $=37 \&$ idforo $=427$ en http://www.google.cl/search?q=calidad+television+chilena+\%2B+educacion\&ie $=\mathrm{UTF} 8 \& \mathrm{hl}=\mathrm{es} \& \mathrm{btnG}=\mathrm{B} \% \mathrm{C} 3 \% \mathrm{BAsqueda}+\mathrm{en}+\mathrm{Google} \&$ meta $=\mathrm{cr} \% 3$ DcountryCL [consulta: 20 junio 2004].

8 Ibid, Carlos Bórquez, 15:52pm, 27-11-2003, Chile. 
$\rightarrow \quad$ Opinión $\mathbf{N}^{\mathbf{3} 3:}$ También es importante recoger la opinión de un joven sudamericano (no es chileno). Se ilustra, por medio de esta opinión, que esta mala influencia va más allá de nuestras fronteras:"Ante todo, quiero decir que la televisión, a pesar de ser un invento extraordinario, es lamentable la finalidad con que se utiliza este medio masivo de comunicación(en su mayoría). Tengo 15 años y me da a mí vergüenza cómo la televisión poco a poco cambia indirecta y paulatinamente nuestra forma de pensar. ¿Quién iba a decir que un niño desperdiciaría horas de juego sano, frente a una caja que cada vez es más violenta, sádica, burda y que empobrece nuestro deteriorado intelecto?. Con esto no quiero decir que toda la televisión sea mala, pero ¿Cómo hacer para que un niño sepa discernir y elegir lo que mira? ¿Cómo hacer para que no se sienta confundido cuando ve a dos personas del mismo sexo besándose?. La televisión PODRÍA ser un magnifico medio de educación... pero lo raro de esto ¿QUIÉN LA MANEJA?"'9

$\rightarrow \quad$ Opinión $\mathbf{N}^{\mathbf{0}} 4$ : "Lamentablemente, y como en todo, la solución depende de nosotros mismos: si es que queremos seguir recibiendo tan sedentariamente lo que se nos mete en la boca cuales borregos, o ser partícipes activos de la programación general cultural de nuestros medios, lo que implicaría crítica constructiva, propuestas y definición de lo que se espera recibir. Debido a esta falta de acción por parte nuestra, la diversidad, el respeto y un mayor interés en la educación (no sólo de los niños, sino que de la sociedad en general), escasean vergonzosamente en nuestra televisión..." 10

9 Ibid, Federico Hidalgo, 20:23pm, 13-11-2003, Argentina

10 LA SEGUNDA, Foro ¿Qué le parece la calidad de la programación actual? Carolina Casanova, 17:39pm, 13-11-2003, Chile en http://www.lasegunda.com/edicionOnLine/Interaccion/Foros/foroactual.asp?pagina=37\&idforo=427 en http://www. google.cl/search? $\mathrm{q}=$ calidad+television+chilena $+\% 2 \mathrm{~B}+$ educacion \&ie=UTF8\&hl= es\&btnG=B\%C3\%BAsqueda+en+Google\&meta $=\mathrm{cr} \% 3$ DcountryCL [consulta: 20 junio 2004]. 
Las distintas opiniones nos llevan a reflexionar sobre muchas cosas, en especial:

$1^{\mathrm{o}}$ Se prioriza como fines de la televisión, por sobre todo, el dinero, el éxito, la ambición, el reconocimiento, y no los valores que puede traer un programa de mejor calidad; los valores se relegan a un segundo plano; no es lo más importante y eso es lo que le inculcamos a nuestros niños

$2^{\circ}$ Nosquedamos "dormidos en los laureles" esperando que los grandes ejecutivos muevan sus fichas de ajedrez como ellos quieran, como si realmente supieran sobre la educación y los valores que necesita la sociedad. Lo más cierto y a la vez angustiante es que todo está en nuestras manos; lo podemos cambiar a través de distintas formas, que se detallarán más adelante, que pueden servir a mejorar la situación caótica que está viviendo está masa humana.

Se espera que las personas que están moviendo estos cordeles a las "marionetas de caja chica", personas hipnotizadas y manipuladas por el poder de la televisión, no se lamenten de los estragos que están provocando en el presente con efectos de largo plazo.

Nuestra reflexión continúa con la prensa escrita, donde se presenta una realidad distinta, pero con un fondo común: una prensa escrita cada vez más frívola que inculca una mal educación.

\section{2) La prensa escrita:}

Desde siempre, la prensa escrita ha podido mantenernos informados del acontecer nacional e internacional y fomentar la educación mediante la lectura, el incentivo del leer cosas de gran interés para la sociedad, donde se presentan comentarios sobre temas del debate público; 
es un lugar donde se puede contactar la gente a través de un papel. Donde una persona cuenta por escrito a otra las novedades en los distintos ámbitos societales. Pero, últimamente y de una manera especial, la prensa escrita se ha contagiado (poco a poco, periódico a periódico) en un medio de frivolidad extrema y la sociedad -o al menos una parte- ha recibido con agrado un ejercicio que se ha transformado en una costumbre: leer los periódicos desde las páginas de atrás hacia las páginas de adelante. Lo más seguro es que la dirección cambiaría si los espectáculos y la farándula estuviese en las primeras páginas.

Lo anterior es producto de la educación que estamos recibiendo, de los hábitos que estamos adquiriendo a través de los años y que mientras no se detenga, no se haga una verdadera voz de alerta, de conciencia, la enseñanza no va a cambiar.

Además, el poder de los "malos educadores" han hecho prevalecer más la vida de los demás que la propia. Esta aseveración puede tener dos posibles explicaciones: ser el reflejo de una vida personal aburrida, sin sentido, sin mayor pretensión, y, a la vez, de un morbo de grandes proporciones. Por otro lado, estas portadas, estas "frases para el bronce" que dicen las personas conocidas dentro de este juego llamado farándula es lo que vende, es lo que trae más ganancias a los poderosos y aquí aparece una vez más la influencia de los "malos educadores" dentro de la sociedad.

La educación debe ser un remedio que actúe rápida y eficientemente frente a una enfermedad tan grave como es el dominio de la prensa más básica por sobre aquella información realmente relevante, que está en las secciones de política, economía, internacionales, entre otras. Más rápido hay que moverse pues está en juego la educación, nuestra riqueza; es lo más preciado que tenemos y no podemos jugar con ella, pues gran parte del futuro depende de su aporte. 
Los diarios justifican su compromiso con la educación por medio de la entrega de fascículos sobre Historia, Ciencias Naturales, Matemáticas y tanto otros temas interesantes que sí aportan al niño y que evidentemente muestran que pueden hacer una mayor contribución que contarnos lo que dijo Anita Alvarado anoche en el programa de televisión de más sintonía. Pero es posible ver en esta entrega de fascículos solamente la idea de cumplir con el apoyo que debe darle a la educación, para que los demás digan posteriormente: ¡¡Oh, cómo se preocupan de la educación!! Algunos diarios, al publicar uno o dos días estos fascículos, creen que tapan toda la puerilidad de que hablan toda la semana.

Es importante destacar que los periódicos -pero no exclusivamente ellos- tienen una responsabilidad sobre sus hombros: el sistema educativo, esto es, las maneras de proceder que son realidades externas e independientes de la voluntad individual ${ }^{11}$, se van transformando de acuerdo a los cambios sociales, culturales, económicos que el país y el mundo van viviendo a lo largo de la historia. Es importante que los periódicos sean un fiel reflejo de la sociedad y de las necesidades sociales y procuren mantener vigente esta responsabilidad y no caigan en la manipulación de información, porque así se perdería un medio que es básico para ayudar indirectamente a los objetivos de la educación de hoy en día. Ver qué necesidades sociales tiene que paliar la educación.

\section{(I) 3) Internet:}

Este es el medio de comunicación masivo que tiene menor edad de existencia, comparado a los dos medios anteriores. A la vez, cada vez es mayor la cantidad de personas que navega en la red. En unos segundos, nos muestra todo un mundo de información, de entretención, de educación y

11 Cadenas Hugo, Apuntes clase de Clase "Teoría Social y Política de América Latina II", Martes 6 de Abril de 2004, Diapositiva N³. 
permite mantenernos conectados, no aislarnos frente este mundo paulatinamente individidualista.

La tecnología de Internet es una precursora de la llamada 'superautopista de la información', un objetivo teórico de las comunicaciones informáticas que permitiría proporcionar a colegios, bibliotecas, empresas y hogares acceso universal a una información de calidad que eduque, informe y entretenga. A principios de 1996, estaban conectadas a Internet más de 25 millones de computadoras en más de 180 países, y la cifra sigue en aumento. ${ }^{12}$

Si bien, Internet ha tenido una noble misión y la entrega de un aporte que es de gran utilidad para muchas personas, la influencia de los "malos educadores", estos "virus" de la educación, entran al ruedo nuevamente por la existencia de páginas que no ayudan a lograr la meta de entregar contenidos morales para la sociedad, para cada uno de nuestros niños, que cada vez, con mayor entusiasmo y más habilidad, están entrando en este mundo cada vez más tenebroso.

Por lo tanto, hay que entrar con un adulto acompañado, con un educador, con una buena influencia para orientar al menor a no caer en las trampas que la violencia, las palabras no adecuadas y la pornografía pueden presentar a los niños. Si se encuentran con una de ellas, hay que tener la capacidad suficiente para poder explicarle de una forma sumamente aleccionadora y educativa sobre las imágenes que ve en la pantalla de un computador, para que el niño pueda entender y discernir entre lo bueno y lo malo, entregándole un papel activo dentro de su proceso de educación. Es bueno que esta lección parta de los padres, que tengan la posibilidad de hablar en familia de este tema, teniendo en cuenta la serie de casos relacionados con la pornografía infantil que han surgido en los últimos años.

12 “Internet”, Enciclopedia Microsoft ${ }^{\circledR}$ Encarta ${ }^{\circledR} 98$ (C) 1993-1997 Microsoft Corporation. Reservados todos los derechos. 
Un caso digno de destacar en sus comienzos, pero de lamentable final, es el que se vivió en Estados Unidos cuando el aumento de las páginas Web que contenían textos y gráficos en los que se denigraba a una minoría, se fomentaba el racismo o se exponía material pornográfico, llevó a pedir que los suministradores de Internet cumplieran voluntariamente unos determinados criterios. En 1996, se aprobó en Estados Unidos la Ley para la Decencia en las Comunicaciones, que convirtió en delito el que un suministrador de servicios transmitiera material indecente a través de Internet. La decisión provocó inmediatamente una reacción indignada de usuarios, expertos del sector y grupos en favor de las libertades civiles, que se oponían a ese tipo de censuras. La ley fue impugnada y, posteriormente suspendida, en junio de 1996 por un comité de jueces federales. ${ }^{13}$

\section{(r) Radio:}

La radio es un último caso que se verá en esta ocasión, pues su relación con la educación es importante y puede servir de gran ayuda la hora de desarrollar la imaginación de los niños. Es el medio de comunicación masivo que se ha caracterizado por su aporte educativo, por la generación de distintas formas de material educativo: radio-teatros históricos (como por ejemplo, sobre el la Guerra del Pacífico, el 21 de Mayo), a través de la música, del baile, de los movimientos, de la creatividad. También existen programas para personas de más edad donde se puede ejercitar el análisis, referido a programas de debate, de noticias, hasta religiosos.

Pero, como todo no es color de rosa, podemos ver ciertos programas radiales que no ayudan en nada a la educación; es más, no les interesa educar. Sólo les interesa entretener de una forma chabacana, burda y de mala cali- 
dad. Por ejemplo, programas caracterizados por "el ventilamiento" de la vida amorosa y / o sexual, programas donde se habla en doble sentido (con jóvenes como protagonistas) o donde existe más que un charlatán rondando por las emisoras, vendiendo pastillas para adelgazar, pulseritas de los "doscientos mil poderes", burlándose de la gente y estafando explícitamente a personas que lamentablemente caen en la “trampa maldita" y que no tienen por qué ser víctimas.

\section{Contribuciones para el mejoramiento de un escenario adverso:}

Si bien hasta ahora se ha mostrado un escenario negro, donde no existe salida posible, éste no es absoluto ni radical, pues han existido hombres y mujeres que, a través de distintas organizaciones, han ayudado al logro del fin de una educación de mejor calidad mediante intervenciones sociales de gran relevancia y de grandes avances para el país . En esta oportunidad, se presentarán dos. En primer lugar, desde la perspectiva televisiva, se presenta el canal de televisión NOVASUR del Consejo Nacional de Televisión. Y, posteriormente, desde el Ministerio de Educación y desde la tecnología computacional, la Red Enlaces.

\section{a) NOVASUR}

Una de ellas es un canal de televisión presentado por el Consejo Nacional de Televisión (CNTV) que tiene como principal objetivo "mejorar la calidad y equidad de la educación chilena a través del uso de la televisión en las salas de clases con programación en consonancia con la Reforma Educacional". Su nombre es NOVASUR TV. 
Este canal está presente desde el año 2000 en 548 colegios rurales y urbanos de las regiones I, II, IV, V, VI, IX, X y XI, abarcando a una población de 226.000 alumnos y 760 profesores capacitados para llevar a cabo este proyecto.

Los establecimientos educacionales que participan en Novasur pertenecen al sector Municipal y Particular Subvencionado, que cubre el $80 \%$ de la matrícula escolar chilena.

Este proyecto cuenta con el apoyo del Ministerio de Educación (Mineduc), el aporte de privados y de fundaciones para contribuir, a través de un uso didáctico de la televisión en el aula, como una herramienta de aprendizaje que mejora la calidad de la educación.

Se transmiten programas televisivos cuyos contenidos se vinculan con el currículum escolar chileno de educación parvularia, enseñanza básica y media. Estos programas constituyen una selección de lo mejor de países tales como Inglaterra, Alemania, Canadá y México, junto a producciones nacionales, especialmente, realizadas para la pantalla Novasur. NOVASUR transmite dos horas diarias de programación de lunes a viernes. Llega a las escuelas y liceos a través de VTR cable -en zonas urbanas- y Sky satélite-en zonas rurales.

Un hito importante, ocurrido el año 2003, fue la implementación del PROGRAMAORÍGENES que Novasur ha instaurado en 162 establecimientos de zonas apartadas del país, en ayuda del desarrollo de la educación de los pueblos originarios (población mapuche, aymará y atacameña).

Una contribución que ha hecho Internet frente a este programa es la posibilidad que el portal www.novasur.cl da a los profesores para que puedan obtener la programación mensual y las guías de apoyo con que cuenta cada programa. También se tiene acceso a videos educativos digitalizados y a material de apoyo para la labor docente. 


\section{b) RED ENLACES}

El Ministerio de Educación (Mineduc), a través de la tecnología, también ha hecho un gran aporte al implementar en 1992 el Programa Red Enlaces como un aporte para el mejoramiento de la Educación Básica. Este programa parte de la base de la construcción de una red de informática educativa experimental en 100 escuelas y 10 instituciones. En 1997, 600 escuelas han sido incorporadas a la red, ampliando sí su cobertura actual del proyecto a un total de 911 establecimientos de educación básica. Cada escuela y liceo, al incorporarse a la Red Enlaces, recibe el software La Plaza, destinado a facilitar el uso del computador por parte de los niños y ayudar al aprovechamiento educativo de las comunicaciones.

Lo destacable de este proyecto es que "la tecnología no se impone a los establecimientos educacionales sino que los profesores, desde su propia perspectiva y realidad, apoyados por los integrantes del proyecto, investigan juntos la manera de integrar gradualmente la tecnología en aquellos temas y problemas que cada uno identifique".

Según fuentes del Ministerio y de los mismos establecimientos, el proyecto ha mejorado significativamente los niveles de creatividad de los alumnos, quienes, a su vez, han aumentado sus niveles de comprensión lectora. Este proyecto, sin duda, ha establecido un vínculo mayor entre el alumno y el profesor, donde la teoría de Durkheim no tiene efectos positivos, pues" La propuesta de educación moral de Durkheim queda así asimilada a una pedagogía tradicional del conformismo y sometimiento, a una metodología didáctica autoritaria. Piaget, por el contrario, enlaza su enfoque con el movimiento de la Escuela activa o nueva, en una moral de la cooperación y de la autonomía, donde la democracia escolar y el maestro como compañero, contribuyan a que los niños y niñas construyan su autonomía moral". 
Ambos son ejemplos de superación, de ganas de hacer cosas para mejorar la situación de la educación en nuestro país, pero a través de las herramientas que hoy son importantes pero en 10 años más serán imprescindibles para cada escuela, colegio, liceo, inclusive universidades. 